unconscious in hysteries, by separating from consciousness, loses something of its dignity, retrogrades in a manner and assumes appearances that recall the action of visceral muscles, the action of lower animals and the action of fatigued muscles.

VII.

HYSTERICAL PARALYSES. DIAGNOSIS.

The latest fashion in medical studies is to apply oneself to the study of hysteric paralyses, and much interesting work has been done on this question. Those patients in whom we observed the preceding phenomena are capable too of completely paralyzing a part of their body. These paralyses appear in about the same circumstances as the other phenomena; they are always brought about by an accident that, while being very slight in itself, is accompanied with a violent moral emotion and with disturbances of the imagination. These traumatic neuroses have been often produced by railway eatastrophes, and some physicians have even adopted the expression of " railway spine." Other circumstances may act, for instance, fatigue, epecially when located in a limb and accompanied by an emotional state as is shown by certain observations. Lastly, there are some paralyses that follow somnambulisms and crises and, as we shall see later on, affect limbs formerly paralyzed or having in them causes of decay.

The most common hysteric paralyses seem to be analogous to the great organic paralyses; the most carefully studied nowadays is central hemiplegia. One half of the body is completely paralyzed; usually, it is true, hysteric paralysis strikes the limbs rather than the face, but the rule is not absolute; when the paralysis is on the right side, for instance, the face and speech may be paralyzed as well as the arm and the leg. In certain cases the diagnosis between hysteria and the apoplectic stroke is very delicate.

The second severe and frequent form is paraplegia in which both legs are completely paralyzed. This accident often appears when an individual is seized with an emotion while walking. The third form we speak of in to-day's lecture will be monoplegia which strikes a limb or a segment of a limb, for these paralyses may be very limited. Discussion is still active regarding the existence of hysteric facial paralysis. Interest also centers on the paralyses of the trunk, as exemplified by a beautiful example of this kind.

The diagnosis of hysteric paralyses is of capital importance and can be made in two manners. First, in an extrinsic manner by examining the symptoms which are foreign to the paralysis itself, the disturbances of the sensibility of the intelligence, the circumstances of appearance, etc. Secondly, you can make this diagnosis by an intrinsic examination which chiefly takes into account the paralysis itself and its clinical characters. This second method appears to be more accurate and scientific and is preferred nowadays. Let us then first give attention to those intrinsic characters. You may first, in certain cases, take into account the localization and the form of the paralysis, and in Austria Professor Freud has insisted a great deal on this point. Notice also the exaggeration of the symptoms, by which we can study the different gait of an organic hemiplegia and of a hysteric hemiplegia, the helicopode and heliopode walk of Charcot; to these positive characters are added negative characters such as absence of atrophy.

We come at last to the question of the reflexes, now considered as very important, chiefly, it must be said, on account of the studies of a French physician, M. Babinski. In a general manner, all the reflexes of a limb must remain normal in an hysteric paralysis. On the contrary, in an organic lesion, a certain number of reflexes must always be injured. A long discussion followed regarding the tendinous reflexes, the epileptoid trepidation, the cutaneous reflexes and the sign given by the toes, the reflexes of the pupils and about the importance of associated movements.

In a word, it is certain that the intrinsic examination gives us exceedingly valuable indications, but these are not absolutely certain signs. One is quite wrong in making things more difficult than they are in refusing the unquestionable services rendered to diagnosis by much more characteristic extrinsic signs.

3. The most important extrinsic sign of all is derived from the examination of sensibility, the modification of which are of the greatest importance in hysteria. Formerly the claw of the devil by the witches and the possessed was a more or less extensive part of the skin in which the subject was insensible to any touch or prick. All the modern authors have much insisted on all the varieties of this phenomenon. As regards the diagnostic of hysteric paralysis, this insensibility must be sought in three organs, - on the skin, on the mucous membranes and in the muscles. Some methods of examining those sensibilities were explained. One of the characters of this anesthesia that plays a most important part in the diagnosis is the localization or the place of the anesthesia, and we must study the forms of geometric segments which can be foreseen. This form of anesthesia is particularly interesting from a clinical and from a psychological point of view. The hysteric patient seems to attend to the popular conception rather than to the anatomical conception.

\section{Briginal articleg.}

\section{ACHYLIA GASTRICA.*}

BY FRANKLIN W. WHITE, M.D.

Assistunt in Theory and Practice of Physic, Harvard Medical School; Physician to Out-Patients at the Boston City Hospital.

Achylia gastrica is a term introduced by Einhorn to denote an absence of gastric secretion, lasting over a greater or less interval of

* Read by invitation of the American Gastro-Enterological Asso* Read by invitation of the American Gastro-Enter.
ciation, at the ninth annual meeting, Boston, 1906. 
time. The gastric contents contain no free or combined $\mathrm{HCl}$, and the ferments are absent, or reduced to insufficient and unimportant traces. The condition is not rare, though the literature of the subject is rather limited, and an accurate knowledge of the condition is largely confined to specialists.

Achylia is a sign of disturbed function of the stomach, which may accompany various disease conditions, such as cancer, severe anemia, and gastric catarrh, and the evidence of recent years tends to show that it also occurs frequently apart from primary organic disease of the stomach or other organs, as a purely functional disturbance.

The history of achylia is closely associated with that of atrophy of the gastric mucosa, and the discovery of a lack of gastric secretion in cancer, and atrophy, led to the false opinion that if no $\mathrm{HCl}$ or ferments were found the diagnosis of cancer or atrophy was justified; and the association of achylia with severe and fatal disease led also to the false belief that it was necessarily a severe condition leading in a short time to death. We know now that an absolute and permanent lack of gastric secretion is compatible with health and happiness, and that the gastric secretion can be spared and compensated for by intestinal digestion. In short, we can make a sharp distinction clinically between $(a)$ secondary achylia associated with cancer, severe anemia, or atrophy of the gastric mucosa, and (b) simple achylia without atrophy, which is a benign condition.

The cases which I wish to report were chosen from the following material: In 235 consecutive cases of chronic disease of the digestive organs which I have recently seen, there were 183 cases of disease of the stomach, consisting of neuroses, ulcer, cancer, catarrh, dilatation, etc., in which the ordinary analysis of the stomach contents was made. In this number, there were 41 cases of subacidity, not including cases of cancer of the stomach or other organs, and in the group of subacid cases were 9 patients in whom there was either entire or almost entire absence of all elements of the gastric juice,- a condition of achylia gastrica. In two of these patients, the condition is undoubtedly the terminal stage of a chronic gastric catarrh; they are only briefly mentioned in this paper; in the other seven, the condition is apparently one of simple primary achylia gastrica.

I have been testing the gastric contents for ferments in all cases in which free $\mathrm{HCl}$ was absent after a test meal and the total acidity very low, and in this manner these cases of achylia were recognized. I believe this condition would be more frequently found if it were carefully looked for.

These cases form an important and interesting group, - important, because of their considerable frequency, and the resemblance of some of them to gastric cancer. Several of the patients came to me with a diagnosis of cancer, and in one a laparotomy was performed, as a result of this diagnosis made by another physician. The patients are all men, whose ages varied from twenty-seven to seventy-three years. They have been under observation for a period varying from ten months to several years, with the exception of two undoubted recent cases in young men, which have been followed only three months. The diagnosis of achylia gastrica has been made from the results of examination of the stomach contents after a test meal in connection with the clinical history and physical examination of the patients.

Method of examination. - Each patient had a thorough physical examination, and the stomach contents, obtained by expression or aspiration three-quarters to one hour after an Ewald test meal was examined as follows: The amount of contents, its appearance, whether well digested or not, and the amount of mucus were noted. The test for free $\mathrm{HCl}$, was made with Gunzburg's reagent, and the total acidity estimated, using phenalphthalein as an indicator. The combined $\mathrm{HCl}$ was tested for occasionally by the qualitative Sjoquist-Ewald method,' but where the total acidity was five or less, in other words, no more than that of the test meal which had been eaten, the test for combined $\mathrm{HCl}$ was considered unnecessary.

The test for lactic acid was made by Uffelman's simple method, and if positive, confirmed by repeating the test with an acid ether extract of the gastric contents. The test for pepsin and pepsinogen was made by the Hammerschlag method. Occasionally no gastric contents could be obtained one hour after the Ewald test meal, in which case the test was repeated and the contents aspirated at the end of three-fourths or one-half hour. The test for rennin and renninzymogen was made by Boas' dilution method. Peptones were tested for by the biuret reaction. In several cases, fragments of mucous membrane were found, which were carefully examined. The examination of the stomach contents was repeated many times in each case.

The stools were examined according to the Schmidt-Strassburger method, especial attention being paid to signs of imperfect gastric digestion, such as residue of connective tissue and muscle fiber. The guaiac test for invisible blood was applied to the acetic acid-ether extract of the stools in each case.

Clinical history. - I will summarize the clinical history of these patients, first speaking briefly for purposes of comparison of the two cases in which the achylia was evidently a sequel to chronic gastric catarrh.

The ages were forty-three and seventy-five. Both had used alcohol and tobacco to excess, and one was an excessive tea drinker. The duration of gastric symptoms was five and ten years respectively. These consisted of distress after meals, especially when hard food was eaten, anorexia, frequent vomiting of slimy stuff, gradual loss of

1 To ten cc. of filtrate add barium carbonate, evaporate to dryness and reduce to ash. Dissolve the residue in water. If, on addition of a solution of sodium carbonate, no precipitate is found, it shows the absence of barium chloride and that no combined $\mathrm{HCl}$ was present. 
10-20 lbs. weight, slight anemia, occasional mild attacks of diarrhea. Physical examination showed nothing abnormal save slight anemia, and malnutrition. The size and position of the stomach were normal. The contents of the fasting stomach consisted of 10-20 cc. thick ropy mucus containing considerable epithelium and leucocytes. The residue after the test breakfast was similar to the cases next to be described. The stools in the older man were thin fluid and foul during attacks of diarrhea, and then and also at other times showed microscopically many well preserved muscle fibers, and considerable connective tissue in small flakes. The stools of the younger man were normal.

The ages of the cases of sinıple achylia gastrica were as follows: Three of them twenty-seven, the others thirty-three, thirty-six, forty-three and seventy-three years. Four were markedly neurasthenic. The course of the illness was variable, and the symptoms were none or many. In one case, there were at first no symptoms referable to either the stomach or bowel, and the examination of the gastric contents was made in searching for an explanation of debility and loss of weight. In one case, there were no gastric symptoms, but the patient came for treatment of diarrhea, which evidently had its source in the stomazh. Oppler, Einhorn and Schmidt have pointed out the relations between achylia gastrica and intestinal catarrhs. In four cases there were gastric symptoms, such as distress after meals, belching of gas, anorexia, also many nervous symptoms, associated with moderate loss of weight, and in two of them occasional attacks of diarrhea. All these patients made some permanent gain in weight under treatment, three of them from 3 to $5 \mathrm{lbs}$., one $8 \mathrm{lbs}$. and one 15 lbs. In none of the patients were the symptoms severe, or even very troublesome. Intervals of comparative health or entire absence of symptoms alternated with relapses due to overindulgence in food, or the result of the weather.

Two of the patients when last seen had had no trouble with stomach or bowel for months. They illustrate well the entire lack of symptoms in achylia when the motility of the stomach is not affected, and the bowel not irritated. The intestine does the work of the stomach, if there is no stasis of food, and no lack of nutrition results. The patients feel perfectly well, and either maintain their weight, or gain materially.

The ultimate course of the achylia is interesting. The gastric secretion in the two patients with chronic atrophic catarrh showed no change for the better, as might be expected. In six cases of simple achylia, the condition has persisted up to the present time; in four, over a period of observation of one to two years, and in two cases for two months.

In one case a return of gastric secretion to approximate normal conditions has occurred. This was a nervous, over-worked student of twenty-seven years, who had suffered for the last seven years with distress two hours after meals, with occasional regurgitation of food.
He was first seen nearly a year ago, when the stomach contents after a test meal showed no free $\mathrm{HCl}$, total acidity 3 , and absence of ferments and their zymogens. This condition persisted unchanged for five months under observation, at the end of which time the gastric secretion was found to be entirely normal, free $\mathrm{HCl} 25$, total acidity 41 , ferments normal. This normal condition has continued without variation up to the present time. No definite explanation of the change can be given. The patient's general condition has considerably improved under rest, careful diet and tonics, but headaches and other nervous symptoms persist. There has been a gain in weight of three pounds only.

Physical signs. - Thorough physical examination of these patients showed no other bodily ailment to which the conditions of the stomach were secondary. One was a slender, overworked student, three were vigorous young men, and three were older men, whose loss of weight, slight anemia and debility made it necessary to consider the possibility of incipient gastric cancer.

Examination of the blood revealed a normal condition, or slight anemia. The red cells varied from $4,500,000$ to $5,400,000$; the white cells from 7,000 to 8,000 and the hemoglobin from $70 \%$ to $100 \%$.

The stomach was found to be of normal size and position in all. Examination of the contents of the fasting stomach showed no signs of chronic catarrh or stasis of food. The characteristic features of the stomach contents were the small amount, little fluid, undigested appearance, absence of free and combined $\mathrm{HCl}$, the complete or almost complete inability to digest proteids when rendered mildly acid $(0.20 \%)$ with $\mathrm{HCl}$, and the complete or almost complete absence of power to coagulate milk. The amount of gastric contents was small $(10$ to $50 \mathrm{cc}$.), often so small that it was necessary to aspirate the contents in less than an hour in order to obtain any residue; this may be due either to the rapid emptying of the stomach, or to the fact that the stomach had lost its power of secretion, and of diluting the gastric contents, or to the thick pasty nature of the residue, which was difficult to aspirate through a tube.

The gastric contents looked like food which had been simply chewed and swallowed, and not digested. No excess of mucus was present, and the microscopic examination of the sediment showed nothing characteristic except fresh blood corpuscles. The filtrate of the stomach contents showed no free $\mathrm{HCl}$, and a total acidity of from 2 to 5 , no greater, in fact, than that of the food taken (the acidity of an Ewald test breakfast of $35 \mathrm{gm}$. of bread well macerated in $300 \mathrm{cc}$. of water, averages 4 to 6 . The mild alkalinity of the saliva which is mixed with it probably has a slight neutralizing effect). Pepsin and pepsinogen were invariably absent in 4 cases, and present in minute traces in 3 . Rennet and rennet zymogen were always absent in three cases, and in 4 gave a positive result in the undiluted 
stomach contents, but negative in dilutions. Lactic acid was absent. No biuret reaction for peptone was obtained.

The work of Hammerschlag, Troller, Gintl and Schiff has shown that the secretion of $\mathrm{HCl}$ and of ferments in the stomach is more or less independent and that either one may be diminished without the other being affected; and Riegel and others have considered the secretion of pepsin more constant than the $\mathrm{HCl}$ function of the stomach. Cases of simple achylia seem to be an exception to the rule, for we have found the ferments very slightly if any more persistent than the HCl. Robin and Schiff have shown that the same conditions may occur in gastric cancer, so that the ferments cannot be used to distinguish simple achylia from cancer.

If we are correct in considering the loss of secretion in our cases to be functional, it is evident that simple achylia forms an exception to the rule laid down by Boas and Cohnheim, that in anacid neuroses of the stomach, the ferment secretion is usually well preserved, while in organic diseases of the stomach, such as catarrhal gastritis, interstitial gastritis and atrophy of the gastric glands, the ferments are diminished or absent. It is evident that the estimation of gastric ferments cannot be relied upon to distinguish neuroses from organic disease of the stomach.

The gastric mucosa was very easily wounded in getting the residue from the test meal, even when a tube with a closed end and side openings was used and the contents expressed instead of aspirated. Fine blood streaks were occasionally seen, and in three instances, small fragments of the gastric mucosa were obtained. These were carefully prepared and examined. Two showed nothing abnormal. One showed a slight degree of granular gastritis. These findings are interesting, but do not necessarily indicate the condition of the stomach as a whole.

The stools were characteristic. In the absence of diarrhea they showed no gross residue or mucus; fat and starch digestion were normal; microscopically an excess of well preserved muscle fiber was often found, and considerable connective tissue in threads and flakes; this occasionally appeared as a fine network through an otherwise normal stool. At other times, the stools were entirely normal. This is in accord with the results of Von Noorden and others, who have shown that digestion may be perfect in achylia.

When diarrhea occurred the stools were light colored, watery, usually foul, mucus was present often with leucocytes, and considerable epithelium and an excess of fatty acids and soaps, and muscle fibers and even connective tissue appeared as a macroscopic residue and as a fine network through the whole tool. This condition clearly shows a lack of gastric secretion, for we know that connective tissue, if not thoroughly cooked through, is only or chiefly digested in the stomach. This "connective tissue reaction" is both delicate and useful; it is the simplest and best sign of the bowel trouble which has its source in the stomach.

The presence of macroscopic meat residue in the feces indicates a disturbance of the intestine also, which was no doubt secondary. We know that the stomach does only part of the work of digesting meat, the greater part is done in the bowels. The hypermotility of the stomach may have also played a part in irritating the bowel by rapidly depositing the food there in an undigested condition. It is evident that the lack of gastric digestion produced a great diversity of results in the bowels, varying from slight functional changes to quite severe catarrh. In several instances, the bowel trouble was so pronounced as to entirely overshadow the stomach symptoms. The presence of connective tissue in the stool was of great value in such cases in indicating the source of the trouble.

The repeated examination of the stool for invisible blood by the guaiac method always gave a negative result, which is important in distinguishing these cases from cancer.

Diagnosis. - We have to distinguish the primary symptomatic achylia, the primary weakness of gastric secretion, from the loss of secretion due to the gastric atrophy of cancer, severe anemia or late chronic catarrh.

The primary cases are characterized by the absence of gastric stasis, the absence of mucus, the small residue from the test breakfast and its chemical character, absent $\mathrm{HCl}$ ferments absent or in traces, lactic acid absent or in traces the vulnerable mucosa, and the absence of invisible blood in the stools. (The physical signs of chronic gastric catarrh or cancer occasionally resemble these closely.) The symptoms are much less characteristic; the nutrition suffers no important change. The patients may be young and vigorous, or neurasthenic and delicate or of middle age and beyond.

The diagnosis is most easily made where a total lack of gastric secretion is found in a patient who is young and vigorous, and whose symptoms are few and of short duration. Where no gastric secretion is found in a middle aged or elderly person who has lost flesh, is weak and somewhat anemic, the diagnosis requires careful and persistent study of the case, and may be very difficult. It is imperative to make a diagnosis between simple achylia and cancer in order to give the patient the benefit of appropriate early treatment, and it is important also to distinguish functional absence of secretion from chronic catarrh. There is often a striking clinical contrast between cases of simple achylia and atrophy, the first young, vigorous and healthy; the second old, weak and suffering from severe anemia.

In simple achylia no true cachexia is present, though loss of weight is common because the patient may eat too little. A long history of gastric symptoms and a permanent gain in weight and strength practically exclude cancer. In simple achylia we do not have occult blood in the stools in the absence of other lesions of the digestive canal. In cancer the permanent 
and abundant presence of occult blood in the stools is the rule. In cancer and in chronic catarrh the acidity of the stomach contents is usually decidedly higher than in simple achylia.

The examination of the fasting stomach is one of the most important means of diagnosis; this is empty in simple achylia while in cancer diminished motility is very much more common, food remains are frequently found, and lactic acid appears early and constantly. The presence of changed blood, mucus, epithelium and leucocytes favor cancer and catarrh.

Martius says that if achylia persists for months without stagnation and fermentation, cancer may be excluded. This is not absolutely true. Cases of well developed cancer of the lesser curvature of the stomach without stasis, or the early stage of any gastric cancer may present this picture, and are peculiarly difficult of diagnosis. The cancer may be latent for a long time, and have only a slight effect upon the general health as long as the motor function of the stomach is preserved and the bowel is normal. We rarely find cases, however, which cannot be diagnosed after close persistent observation.

The vulnerability of the gastric mucosa is not a distinctive feature of simple achylia. Fine streaks of blood and occasional shreds of mucosa are found in the gastric contents in all organic diseases of the stomach, in association with anacidity according to Cohnheim and Kuttner, though perhaps more frequently, more abundantly and as an earlier sign in cancer than in any other condition. Fragments of mucosa dislodged by the stomach tube tell us little about the stomach as a whole and have little value in diagnosis except in occasional lucky instances.

Cases of chronic gastric catarrh are often easily distinguished from simple achylia by the presence of an exciting cause,--misuse of alcohol, tobacco or cathartics, hasty and irregular meals, etc., the long duration of symptoms, the frequent appearance of mucus, the numerous epithelial cells in the stomach contents and wash-water.

The question of exploratory laparotomy for diagnosis is a very important one. We have seen that most cases of achylia, especially in young persons, present no great difficulties in diagnosis, but there is a group of cases in middle life and old age, where the suspicion of incipient gastric cancer is strong, where it is not wise to delay the diagnosis long lest the time for satisfactory treatment shall pass by. The necessity for early diagnosis in cancer is self-evident, and the question of exploratory laparotomy for the purpose is very important. The surgeons have blamed the physicians for keeping such cases too long under observation in attempt at diagnosis, and insist that every case where cancer is suspected should have an early surgical diagnosis in the belief that it is better to open many normal abdomens than to fail to discover and treat a gastric cancer before it reaches an inoperable stage.

On the other hand, we must not forget that even in recent years an exploratory laparotomy, except in especially selected cases, is an operation which carries a very decided immediate risk to life and it tends also to make the physician superficial in observation, because he knows that the diagnosis will be made at operation. I have seen a considerable number of laparotomies done in the last few years in which no lesion of the stomach was found, and not infrequently conditions were discovered which might have been diagnosed without operation. Occasionally the exploratory operation has been followed by a most unhappy fatal result.

I am a firm believer in the value of exploratory laparotomy for the purpose of diagnosis, but it should only be performed in carefully chosen cases, and after the patient has been, for several weeks at least, under constant expert medical supervision. In three of these cases, aged fortythree, forty-six and seventy-three, an exploratory operation was considered, but not advised, as the diagnosis became reasonably clear without it, and the subsequent history of the patients has justified this course. One of the patients aged seventy-five, in which a diagnosis of achylia secondary to chronic catarrh had been made, was seen by another physician who made the diagnosis of gastric cancer, and advised a laparotomy. At operation no gross lesion of the stomach was found. The patient, I am happy to say, recovered promptly from the operation and is as well as before.

Prognosis. - The prognosis in cases of simple achylia is good regarding life. The bowel may do the work of the stomach and the patient be free from symptoms and gain weight under careful treatment. My patients gained from three to fifteen pounds each. Ewald reports a case which gained forty-two pounds.

The fact that patients with achylia may remain in good physical condition so long as the stomach empties itself properly and no opportunity occurs for local fermentation of food, does not indicate that the stomach is an unnecessary organ and serves mainly as a reservoir for food. Such persons are rather in a state of unstable equilibrium, which may be easily upset. Achylia is a disease, not an anomaly, and persons who have it are much more sensitive than normal persons to gastric stimuli and irritants. If there is intestinal indigestion also the prognosis may be serious. The fact that patients who have had achylia for years may in rare instances recover normal secretion should teach us never to give up hope in the individual case, but I see no way at present of telling in advance in which patient this is likely to occur, though the literature and my own experience indicate that such a change is confined to the neurotic cases.

Treatment. - The indications are to treat the general condition, the neurasthenia and anemia by appropriate measures, and secondarily care for the digestion. In treating the stomach, we try to do three things: (1) To stimulate and reestablish gastric secretion; (2) to compensate for its loss by artificially aiding digestion in those cases in which the pancreas is unable to do all 
the work; (3) to protect the motor functions of the stomach and avoid stagnation and fermentation of food.

I consider the last two indications much more important than the first. I have had no success with measures aiming to re-establish secretion, and in reading over the reported cases, now considerable in number, in which normal secretion has appeared after months or years of absence, it is not evident that the treatment has had much to do with the result.

The remedies chiefly used for this purpose are $\mathrm{HCl}$ bitters, stimulant foods, the stomach douche and electricity. $\mathrm{HCl}$ medication is usually useless, though we all know patients who, as Martius says, take 5 to 10 drops of officinal $\mathrm{HCl}$ in water after meals and insist that they feel badly without it and with it have no indigestion. It is difficult to see how this dose can have any value apart from auto-suggestion; 10 or 15 drops in water before, during and after meals may accomplish more. Biedert who was himself afflicted with achylia gastrica took 120 drops of dilute $\mathrm{HCl}$ daily. Chittenden has pointed out that $2 \frac{1}{2}$ liters of $0.2 \% \mathrm{HCl}$ will be needed daily with a consumption of $100 \mathrm{gm}$. of proteid and yet none will be left over as free acid which is necessary for the action of pepsin. Given without pepsin it has no value as a digestant in the stomach, and with pepsin it is useless because not enough can be given to leave free acid. It is useless as an antiseptic, a stimulant to pancreatic secretion, or stimulant to gastric motility for the same reason, and fortunately it is not needed for the latter purpose as stasis is rare in simple achylia. $\mathrm{HCl}$ medication has not proved useful or necessary in my hands; the patients have remained well without it, and have recovered from acute attacks of indigestion without it.

If there are signs that the pancreas cannot fulfill the demands made upon it, it is more useful to remodel the diet, or to give pancreatic extract or other ferments active in the bowel. These cases without $\mathrm{HCl}$ seem to be the ideal ones for the use of pancreatin. In most cases diet without drugs is sufficient. We know that the pancreas usually compensates for the lack of gastric juice and the discovery of achylia in a comparatively healthy person is not an indication for the use of drugs calculated to stimulate secretion. A perfectly compensated digestive apparatus needs them no more than the compensated heart needs digitalis. A careful regulation of the diet has proved the most important part of the treatment. In selecting the diet it is more important to choose food which will favor the mechanical work of emptying the stomach, and will leave it readily than to seek out those suited to the lack of secretion. This means food so finely divided that it will go through a sieve, brothy foods, vegetable purées, finely chopped meat, not a bulky diet. Butter is very useful. Fine division of the food by chopping, cooking and chewing also lessens the work of the bowel. The patient must eat. He has perhaps decided that one or another food disagrees with him.
One doctor has forbidden this food and another that until he eats far too little. The main thing with ill-nourished patients is to feed them well.

Adolph Schmidt has pointed out that the connective tissue diarrhea of achylia has given us a valuable indication for the treatment of the intestinal disturbance. The absence of the antiseptic action of $\mathrm{HCl}$ of the stomach has been considered the cause of these bowel troubles, but the $\mathrm{HCl}$ is only a factor in keeping down the fermentation, for two thirds of the patients with achylia have no bowel trouble. In general, lessened motility of the stomach has greater significance as a cause of bowel trouble than disturbances of secretion. When food leaves the stomach slowly, germs of fermentation and putrefaction establish themselves there more easily, and are emptied into the bowel, and in this fashion cause secondary trouble. This, however, is not important in simple achylia as stasis of food in the stomach very rarely occurs. The most important factor is a lack of digestion of connective tissue in the stomach. The bowel cannot digest raw or smoked connective tissue, and if this is not digested before leaving the stomach, it goes through the bowel practically unchanged. Gastric digestion of meat, of fat and of starch is not so important, because here the bowel secretion may compensate for it in a general diet. Where meat is not finely divided it is not only the connective tissue which is lost when the stomach does not do its work, but also the inclosed muscle and fat. Pieces of meat and fat may appear in the stool. This overloading the bowel with undigested material is very important as a cause of diarrhea and finally of catarrh of the bowel.

The number of intestinal bacteria depends largely on the quantity of food at their disposal. The better the food is digested, the fewer the intestinal bacteria. Many cases of diarrhea are undoubtedly explained by the growth of germs of fermentation and putrefaction in poorly digested food residue. If the patient over-eats he gets a diarrhea, not because he has swallowed too many bacteria, but because he has too much undigested food in the bowel which serves as a culture media for these omnipresent germs. No intestinal antiseptic or cathartic has any marked effect on the number of intestinal bacteria. Their number can be kept down only by taking away their food.

The indications for treatment to be drawn from this are briefly that we must not give patients with achylia raw, rare or smoked meat. We have seen that the bowel is unable to digest raw connective tissue and we must exclude it unless it can be shown that the use of raw and smoked meat has definite advantages of another sort over well-cooked meat. The experiments of Pawlow have shown that the use of raw flesh stimulates the secretion of the digestive fluids which is especially important in gastric anacidity. If we compare, however, the advantage of stimulating secretion with the disadvantage of a large amount of indigestible connective tissue, we 
find the latter is most important, and secretion can be equally well stimulated by means of meat extract, bouillon, etc.

Etiology. - We can only briefly consider the etiology of this interesting condition. It used to be generally assumed that achylia gastrica developed only after severe organic disease; and the atrophy of the gastric glands associated with cachexias, cancer of the breast, pernicious anemia, etc., has been carefully studied post-mortem by Fenwick and others. Since the introduction of the stomach tube cases of atrophy which were associated with pernicious anemia, cancer, senility and the terminal stage of chronic gastritis have been diagnosed during life. We have seen, however, that there is a large group of cases in which the achylia is not associated with these severe diseases, and does not threaten life, and which consequently have been very little studied in the autopsy room. In these there is no history of gastritis or other definite cause. They are apparently chiefly functional cases in which the glandular elements are not usually greatly altered, though they do probably change after long disuse. Analogy is seen in the kidney where the function may be suspended without atrophy of the organ, and in the atony of the stomach and bowel without organic change seen so frequently and persistently in neurasthenia and hysteria.

The etiology of this simple achylia gastrica is an interesting biological problem with a practical side. A well-known and important function is absent without definite cause, or apparent results. The latter may be explained by compensation. The intestinal digestion is so powerful that gastric digestion seems almost superfluous. It is not, however, simply an anomaly, the disappearance of a function which is unnecessary for the organism, ( $c f$. Darwin), it is a diseased condition. The individual with achylia is worse off than his mates, - he is in a state of unstable equilibrium, and bowel trouble may be a real danger. The fact that achylias are neurasthenic is not a sufficient reason to consider this the cause. We find neurasthenia without loss of secretion, and loss of secretion without neurasthenia.

Martius considers it a primary weakness of secretion which is either congenital or develops on the basis of a predisposition. The hereditary element is interesting. Cases have been reported in a mother and daughter, in two brothers, etc. An anatomical basis for the condition has been suggested. Hemmeter cites ten cases of achylia which do not include cases of cancer or chronic gastric catarrh, in nine of which fragments of the mucosa obtained through the tube were examined. These all showed signs of granular gastritis and atrophy. Hemmeter questions whether the condition is ever a neurosis. The changes in the mucosa, however, seem far too slight to explain the striking change in function (compare the conditions in gastric cancer where the secondary change in the mucosa leads to achylia only when it has advanced to atrophy), and the granular gastritis may be the result not the cause of the achylia. It is not satisfactory to use the evidence from fragments of mucosa, obtained through the stomach tube, to settle a question of secretion which is the expression of the function of the whole stornach. In addition we have seen one case similar to those reported by Einhorn and others, of recovery of gastric secretion after a long period of achylia showing that achylia may exist when the glands of the stomach have not been totally destroyed (as shown by their recovery of secretion). In such cases the condition is probably due to nervous influences with partial atrophy, but no autopsies have been reported and the atrophy can only be conjectured, not proved. In short, cases of achylia may be divided into two groups: First, the severe and striking cases which were earliest reported in which there is unquestioned atrophy of the mucous membrane (either idiopathic or secondary to some serious condition such as cancer of pernicious anemia), and second, the group of cases which are by no means rare, in which achylia occurs in neurasthenic weak persons, those of middle life and beyond, where the condition is simply that of a weak stomach with feeble secretion.

In conclusion, I wish to emphasize these points:

(1) Simple achylia gastrica is a relatively common condition. It made up nearly $5 \%$ of this group of cases.

(2) The diagnosis must be made from the physical examination of the patient and his stomach contents and feces. The symptoms are not characteristic.

(3) Cases in which there is entire lack of $\mathrm{HCl}$ secretion, but in which very minute traces of pepsin or rennin are retained are not achylia in the strictest sense of the word, but are best classified as achylia.

(4) In making the diagnosis of gastric cancer, remember the frequency of simple achylia, which may resemble it closely. The examination of the feces for invisible blood is especially useful here.

(5) The etiology of simple achylia is unproved; its course suggests a functional origin.

(6) Its most satisfactory treatment is hygienic and dietary..

Condensed histories of the seven cases of simple achylia gastrica follow:

Case I. Age twenty-seven. Student. Pleurisy ten years ago. No tobacco or alcohol. Very nervous and overworked. For seven years distress two hours after meals, now all the time. Regurgitation of food. Headache. Weakness, dizziness, appetite good, bowel regular, no vomiting. Best weight two years ago 136 ; now 121. Objective examination: Slender and rather thin. Hemoglobin $85 \%$. Reds $4,800,000$. Whites 8,000. Stomach: Fasting contents, 23 cc.: No free $\mathrm{HCl}$, residue normal. Contents after test meal, 30 to 50 cc.: no free $\mathrm{HCl}$, total acidity 4 to 6 , Pepsin 5 to $7 \%$, rennet positive in undiluted contents only. Streaks of blood (tube). Stools: Usually normal, occasionally microscopic excess of meat fibers and connective tissue. Guaiac negative. The patient's general condition improved considerably under rest, diet, tonics and careful hygiene, but the achylia persisted un- 


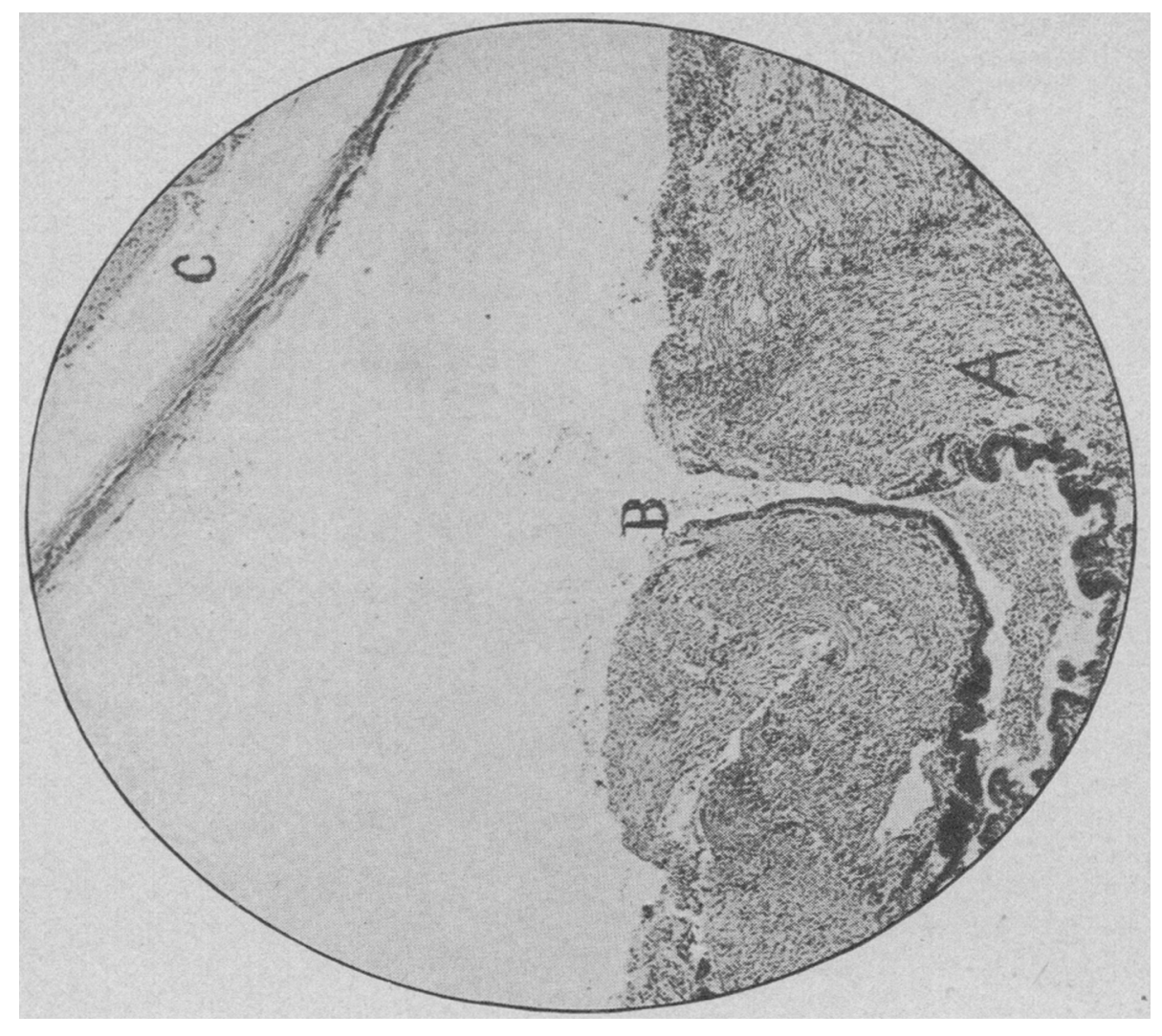

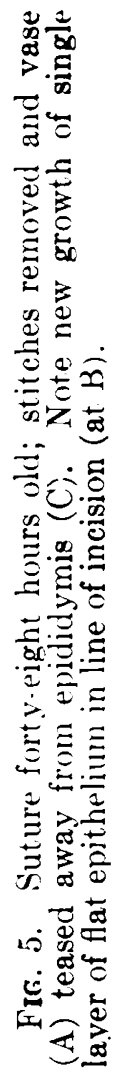

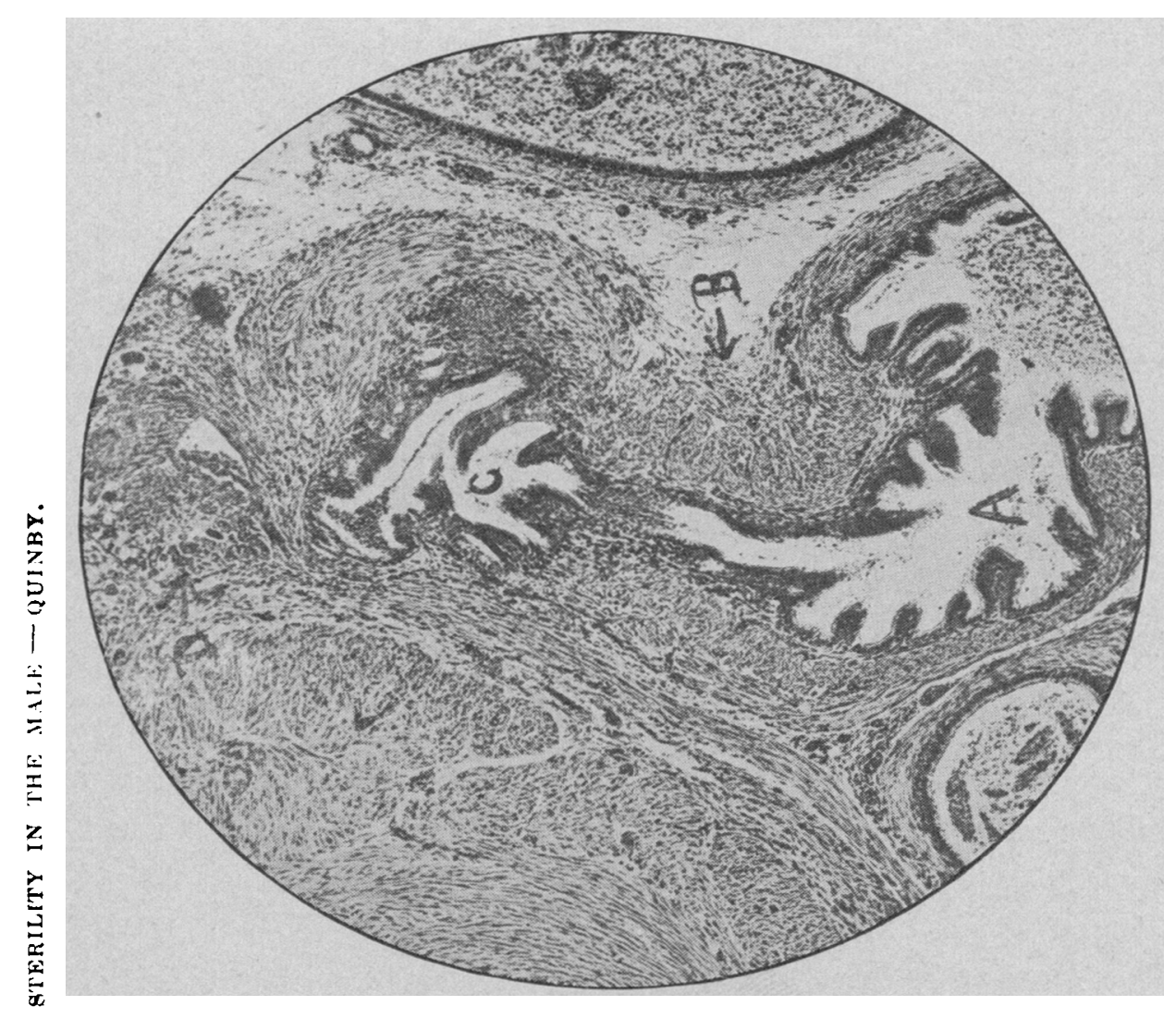

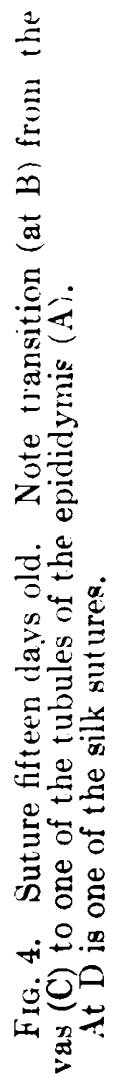

The Boston Medical and Surgical Journal as published by 
changed for five months under observation, at the end of which time the gastric secretion was found to be entirely normal. Free $\mathrm{HCl}, 25$. Total acidity 41 . Pepsin $80 \%$. Rennet positive in 1-300 dilution. Several examinations in the last six months show that this normal condition has continued without variation. Headaches and other nervous symptoms persist.

CASE II. Age twenty-seven. Laborer. Family and previous history good. Tea slight excess. Tobacco moderate. No alcohol. For six months gas and distress after meals. Bowels regular. Best weight 160, now 154. Physical examination: Vigorous, young man. Not neurotic. Hemoglobin $95 \%$. Reds $5,400,000$. Whites 8,000. Stomach, fasting contents, 20 cc.: Clear fluid. No free $\mathrm{HCl}$. Contents after test meal 20 to $50 \mathrm{cc}$.: No free $\mathrm{HCl}$. Total acidity 2 to 4. Pepsin 0. Rennet positive in undiluted contents only. Stools: Normal, except for excess of microscopic meat fiber and connective tissue. Guaiac negative. General improvement under treatment, gained 5 lbs. Stomach contents have remained the same during the last year.

Case III. Age twenty-seven. Merchant. Previous history good. Alcohol and tobacco very moderate. Neurotic temperament. For ten months distress after meals. Poor appetite. Belching of gas. Bowels regular. Objective examination: Well developed and nourished. Hemoglobin 90. Reds 5,400,000. Whites 7,400. Stomach contents, after test meal, 47 cc.: No free $\mathrm{HCl}$. Total acidity 1. Pepsin 0 . Rennin 0. Stools: Normal, except for moderate excess of microscopic meat fiber and connective tissue. Guaiac negative, with meat-free diet. General improvement under treatment, gain of $4 \mathrm{lbs}$. Several examinations during the last year showed that the achylia remains absolute.

Case IV. Male. Age thirty-three. Carpenter. Previously well. No bad habits. Two months occasional attack of diarrhea with colic. No gastric symptoms. Headache. Fair appetite. Sleeps well. Neurasthenic. Objective examination: Nutrition good. Healthy appearance. Hemoglobin $90 \%$. Reds $4,800,000$. Whites 7,000. Stomach contents, after test breakfast, 30 cc.: No free HCl. Total acidity 5. Pepsin $10 \%$. Rennet positive in undiluted contents, not in dilutions. Stools: Watery, foul, with mucus and excess of calcium soaps, and very many well preserved muscle fibers. Guaiac test negative, with meat-free diet. On careful diet and rest, subjective symptoms disappeared,. When last seen, had no trouble with stomach or bowels for several months. Gained $5 \mathrm{lbs}$ The achylia remained almost absolute.

CAse V. Age thirty-six. Shoemaker. No previous illness except "lung trouble," four years ago, from which he entirely recovered. For one year distress several hours after meals. Gas, sour taste, rarely vomits. Fair appetite. Bowels irregular. Very nervous. Best weight three years ago, 180, now 161 . Physical examination: Healthy appearance. Hemoglobin 85\%. Reds 5,200,000. Whites 7,500. Fasting stomach empty, contents after test meal, 30 cc.: $\mathrm{No}$ free $\mathrm{HCl}$. Total acidity 2 to 5 . Pepsin 5 to $12 \%$. Rennin positive in 1-1 to 1-10 dilutions. Blood streaks. Fragment of gastric mucosa in wash-water was normal. Stools: At times practically normal. At other times thin fluid, with macroscopic residue. Mucus, excess of microscopic muscle fibers. Guaiac negative. Under suitable treatment patient became almost entirely well. Stomach contents remained the same during the last three months. Achylia without stasis.

CAsE VI. Age forty-three. Merchant. Previous history good, except for considerable alcohol at times.
For two months, distress after meals. Afraid of solid food. No vomiting. Headache. Belching of gas. Constipated at times. Many nervous symptoms. Weight three months ago, 165, now 142. Physical examination: Well developed, fairly nourished. Sallow. Poor teeth. Hemoglobin 75\%. Reds 4,500,000. Whites 8,000. Fasting stomach, no residue obtained. After test breakfast 10 to 50 cc.: No free HCl. Total acidity, 2 to 6 . Pepsin 0. Rennin positive in undiluted contents only. Occasional blood streaks. Fragment of gastric mucosa found in washwater was normal histologically. Stools: Pasty. Macroscopic meat at times. Mucus, calcium soaps. Guaiac negative.

Patient slowly and steadily improved; in subsequent ten months, gained 8 lbs., but the above symptoms persisted in milder degree. Frequent examinations demonstrated the persistence of the achylia. A suspicion of early cancer was raised by the age, rapid loss of weight, slight anemia and anacidity, but the course of the disease and the persistent absence of blood from the stools have vindicated the diagnosis of simple achylia.

Case VII. Age seventy-three. Retired coachman. Always well till present illness. No tobacco or alcohol used. Occasional attacks of diarrhea in last few months. Stools 2 to 4 a day for 3 or 4 days. No distress or pain after meals. No vomiting. Appetite good. Feels weak and a little short-winded. Has lost 21 lbs., in the last year. Physical examination: Well developed. Fairly nourished. Hemoglobin 70\%. Reds 4,500,000. Whites 7,000. Stomach, fasting contents 5 cc.: No free $\mathrm{HCl}$. No mucus or food. After test breakfast 10 to 40 cc.: No free $\mathrm{HCl}$. Total acidity, 2 to 5 . Pepsin 0 . Rennin 0 . Fragment of gastric mucosa showed slight granular gastritis. Stools: Pasty, foul, mucus, with leucocytes and epithelium, occasionally gross meat and connective tissue residue. Excess of fatty acids. Guaiac negative with meat-free diet. General condition steadily improved under careful diet and iron. Fifteen lbs.,weight was gained in ten months. Attacks of diarrhea ceased and patient felt well and returned to light work. Frequent examinations showed the continuance of absolute achylia. A diagnosis of cancer was made in this case by another physician, but our diagnosis of simple achylia was verified by the course of the illness. REFERENCES.

Boas: Magenkrankh. Ieipzig, 1903.

Cohnheim: Die Krankh. der Verdauungs. Berlin, 1905

Sinhorn: New York Med. Rec., 1892, vol. xli, p. 650. Ibid., 1895, 1903 , vol. ix, p. 147. Am. Jour. of Med.' Sc., 1902, vol. 124, n. s., p. 571 .

Fenwick: An Atrophy of the Stomach. London, 1880.

Gintl: Arch. für Verdauungs., 1898, vol, iv, p. 251.

Martius: Achylia Gastrica ihre Ursachen und ihre Folgen mit ein

Martius: Achylia Gastrica ihre Ursachen und ihre Folgen mit ein
anatomischen Beitrag von Prof. Lubarsch. Leipzig and Vienna, 1897.

Oppler: Deut. med. Wochen

Pawlow: The Work of the Digestive Glands. Iondon, 1902.

Pawlow: The Work of the Digestive Glands.

Robin: Arch. für Verdauungs., 1902, vol, x. p. 242.

Schiff: Ibid., 1900, vol. vi, p. 107.

Schiff: Ibid., 1900, vol. vi, p. 107.

Schmidt, A.: Deut. med. Wochensehr.

Von Noorden: Zeitschr. für klin. Med., 1890, vol. xvii.

\section{STERILITY IN THE MALE: ITS OPERATIVE TREATMENT WHEN DUE TO BILATERAL} EPIIJIDYMITIS.

BY WM. C. QUINBY, M.D., Bosto..

THE fact that a certain definite percentage of sterile marriages are due to the fault of the husband is one which, though well known, cannot 